\title{
A Study of Reproductive Morbidities among Women Reporting to Primary and Tertiary Care Centres in and around Delhi
}

\begin{abstract}
Purpose: To assess reproductive morbidities among women reporting to a tertiary and a primary health centres in and around Delhi, India.

Methods: 581 women (388 were from Safdarjung Hospital and 193 from the Primary Health Centre in Najafgarh) of all age groups who attended the gynecological out-patient departments at both centres were interviewed using a structured questionnaire comprising of questions relating to general socio-demographic information and the reasons for coming to the centre and examined. These were categorized into gynecological, obstetrical or contraceptive after obtaining a detailed history.

Results: The frequency of reproductive morbidities in the present study was observed to be quite high with gynecological conditions being the most common (88.64\%), followed by obstetric (65.93\%) and contraceptive (11.53\%) morbidities.

Conclusion: Gynaecological conditions were the major reasons while the women visited the healthcare facilities. Early identification of RTIs and other types of morbidities needs to be encouraged through regular check-ups. The antenatal clinics also need to be strengthened in order to ensure better obstetric health care.

Keywords: Contraceptive, Gynecology, Morbidity, Obstetrics, RTI.

Sweta Rajani $^{1}$

Harsha S Gaikwad ${ }^{1}$

Vrijesh Tripathi ${ }^{2}$

Sudha Salhan ${ }^{1}$

${ }^{1}$ Department of Obstetrics \& Gynaecology, Vardhman Mahavir Medical College \& Safdarjang Hospital, New Delhi, India-110029

${ }^{2}$ Department of Mathematics and Statistics, Faculty of Science and Agriculture, The University of the West Indies, St Augustine, Trinidad and Tobago.

*For correspondence:

Email: vrijesh.tripathi@ sta.uwi.edu
\end{abstract}

This article is available in Embase, Index Corpenicus, Scopus, PubsHub, Chemical Abstracts, Socolar, EBSCO, African Journal Online, African Index Medicus, Open-J-Gate, Directory of Open Access Journals (DOAJ) databases

\section{Introduction}

Maternal and child health is one of the eight basic components of primary health care in the Declaration of Alma-Ata ${ }^{1}$. Even as prevention of maternal mortality has been identified as a priority, little attention is given to the reproductive health of non-pregnant women. In third world countries, such women tend to encounter the health care system mostly when they are the target of family planning programs.

Since the 1994 International conference on Population and Development in Cairo and the

Int J Health Res, March 2011; 4(1): 29 
Rajani et al

1995 World Congress on women in Beijing, attention has been given to comprehensive women's health in general. ${ }^{2}$ The most significant achievement was the shift in orientation from fertility reduction and population policies to reproductive health. Reproductive health has been defined as "the ability to live through the reproductive years and beyond with reproductive choice, with dignity and successful child bearing, free of gynecological disease and risk." ${ }^{3}$ According to WHO estimates, reproductive illhealth accounts for $33 \%$ of the total disease burden in women as compared to $12.3 \%$ for males. Despite the significant difference, the magnitude of reproductive morbidity has not been adequately defined, especially in many South Asian countries. ${ }^{4}$ Reproductive morbidities remain a major challenge to the scope and outreach of health care system in India. This study gives baseline data about reproductive morbidities among women reporting to a tertiary care centre and a Primary Health centre in and around Delhi. The objective was to assess and suggest modifications to the health care system in both a rural and urban setting.

\section{Methods}

This was a cross-sectional study conducted at the gynecological clinic at Vardhman Mahavir Medical College and Safdarjung Hospital (SJH) (a tertiary level hospital) New Delhi, India and Primary Health Centre at Najafgarh (PHC), which is a rural health training centre near Delhi. A total of 581 women (388 from SJH and 193 PHC Najafgarh) of all age groups who attended the General Out-patients Department (GOPD) at both the centres were interviewed using a structured questionnaire comprising of questions related to general socio-demographic information such as place of residence, religion, marital status, age, age at marriage, cohabitation and first pregnancy, literacy and family income. The women then underwent a general physical examination with anthropometric measurements followed by a local examination and hemoglobin level estimation. Urine examination was done in women with symptoms of urinary tract infections. Vaginal smear examination and VDRL testing was done in women with history of reproductive tract infections (rTI) and sexually transmitted
Reproductive Morbidities Among Women

infections (STI). Endometrial sampling, hormonal studies and ultrasonography were done on women with menstrual symptoms. Anemia in non-pregnant females was diagnosed as hemoglobin of less than $11 \mathrm{~g} / \mathrm{dl}$ and in pregnant females at less than $10 \mathrm{~g} / \mathrm{dl}$.

Cases of reproductive morbidities were categorized into gynecological, obstetric or contraceptive after obtaining a detailed history. The information on obstetric morbidity was collected only by the interview-questionnaire method from a sub-sample of women who had experienced a pregnancy in the last two years.

Statistical analysis was done using SPSS version 12 (SPSS Inc, USA). Independent t-test and chisquare or Fisher's Exact test (for small data) were applied as appropriate. At $95 \%$ confidence interval, p-values less than 0.05 were considered significant.

\section{Results}

Most of the women were predominantly Hindus under 35 years of age. The mean age of these women was 29.64 years $(\mathrm{p}=0.002)$ (Table 1$)$. The age, mean age at marriage and cohabitation and age at menarche was significantly higher for those at the Safdarjung Hospital than those at the Najafgarh PHC $(\mathrm{p}<0.000)$. The average number of female children was higher at SJH $(\mathrm{p}<0.001)$ than at Najafgarh PHC. While $76 \%$ women of those who attended SJH had urban background, $81.3 \%$ women attending the PHC were from a rural areas.

The mean height was $153.25 \mathrm{~cm}$ which was significantly lower at $\mathrm{SJH}$ than Najafgarh PHC $(\mathrm{p}<0.001)$. Anemia was found to be very common, with $61.6 \%$ women at Safdarjung Hospital and almost all the women at PHC Najafgarh having clinical pallor. None of the women had severe anemia. A pathological vaginal discharge was present in about one third of the study subjects (Table 2). Gynecological morbidity $(88.64 \%)$ was most common at both the centres, followed by obstetric $(65.93 \%)$ and contraceptive $(11.5 \%)$ morbidity. Many women complained of more than one type of morbidity but none of them complained of sexual morbidity

Int J Health Res, March 2011; 4(1): 30 
Table 1: Socio-economic characteristics

\begin{tabular}{|c|c|c|c|c|}
\hline Covariates & PHC & SJH & Total & p-value \\
\hline \multicolumn{5}{|l|}{ Residence } \\
\hline Urban & 36 & 295 & 331 & \\
\hline Rural & 157 & 93 & 250 & $0.000 *$ \\
\hline \multicolumn{5}{|l|}{ Religion } \\
\hline Muslim & 8 & 30 & 38 & \\
\hline Hindu & 185 & 385 & 543 & 0.100 \\
\hline Per capita income & $829.7 \pm 835.7$ & $862.4 \pm 843.5$ & $851.5 \pm 840.0$ & 0.657 \\
\hline \multicolumn{5}{|l|}{ Self education } \\
\hline Illiterate & 87 & 208 & 295 & \\
\hline Primary & 14 & 50 & 64 & \\
\hline Secondary & 56 & 82 & 138 & \\
\hline Graduate and above & 36 & 48 & 84 & $0.006 *$ \\
\hline \multicolumn{5}{|l|}{ Husband education } \\
\hline Illiterate & 71 & 140 & 211 & \\
\hline Primary & 12 & 37 & 49 & \\
\hline Secondary & 36 & 85 & 121 & \\
\hline Graduate \& above & 70 & 112 & 182 & 0.058 \\
\hline \multicolumn{5}{|l|}{ Number of children } \\
\hline NA & 39 & 107 & 146 & \\
\hline$\leq 1$ & 37 & 54 & 91 & \\
\hline$\geq 2$ & 117 & 227 & 344 & 0.076 \\
\hline \multicolumn{5}{|l|}{ Male } \\
\hline NA & 45 & 118 & 163 & \\
\hline$\leq 1$ & 91 & 144 & 235 & \\
\hline$\geq 2$ & 57 & 126 & 183 & 0.053 \\
\hline \multicolumn{5}{|l|}{ Female } \\
\hline NA & 45 & 117 & 162 & \\
\hline$\leq 1$ & 116 & 177 & 293 & \\
\hline$\geq 2$ & 32 & 94 & 126 & $0.004 *$ \\
\hline
\end{tabular}

The most common gynecological morbidity reported was rTI in the hospital setting with $35.6 \%$ having symptoms of lower rTI while $31.7 \%$ had symptoms of upper rTI. Of the 241 (41.5\%) females with history of rTI, only 176 (30.3\%) had clinical findings suggestive of rTI with a similar distribution at both the centres. Interestingly, one in every ten women at either centre was found to be harboring rTI without any symptoms of the same $(9.5 \%$ in SJH and $10.4 \%$ at $\mathrm{PHC}$ ).

Menstrual dysfunction (36.83\%) and infertility $(21.6 \%)$ were the second and third most common finding respectively. More women at PHC (66.1\%) complained of irregularity in mensus than at SJH (55.41\%). Six women at each clinic associated it with a recent child-birth. Almost one -fifth of women complained of oligomenorrhoea with an interval of cycle more than 35 days while $13.76 \%$ had polymenorrhoea. Of those reporting infertility, $67.2 \%$ had primary infertility and $32.8 \%$ had secondary infertility. The percentage of women with primary infertility was higher in PHC (77.1\%) than at SJH (64.4\%).Women with secondary infertility after repeated abortions presented more frequently at $\mathrm{SJH}(36.59 \%)$ and those with one live issue presented most commonly in PHC (63.41\%). The PHC had a higher number of women with prolapse $(6.9 \%)$ as compared to SJH (5.8\%). $80 \%$ women at SJH and 
Table 2: Reproductive history of women at Najafgarh PHC and SJH Hospital

\begin{tabular}{|c|c|c|c|c|}
\hline Covariates & PHC & S J Hospital & total & $\mathrm{p}$-value \\
\hline \multicolumn{5}{|l|}{ Marital status } \\
\hline Married & 185 & 358 & 543 & \\
\hline Unmarried & 8 & 30 & 38 & 0.100 \\
\hline Age (years) & $28.03 \pm 8.47$ & $30.44 \pm 8.90$ & $29.64 \pm 8.81$ & $0.002 *$ \\
\hline Age at marriage (yr) & $16.17 \pm 2.79$ & $16.87 \pm 3.76$ & $16.63 \pm 3.40$ & $0.025^{*}$ \\
\hline Age (yr) at cohabitation & $17.43 \pm 2.88$ & $17.68 \pm 3.53$ & $17.60 \pm 3.33$ & 0.405 \\
\hline Height $(\mathrm{cms})$ & $155.45 \pm 4.70$ & $152.15 \pm 4.56$ & $153.0 \pm 4.87$ & $0.000 *$ \\
\hline Weight (kg) & $53.23 \pm 5.13$ & $52.38 \pm 7.39$ & $52.66 \pm 6.73$ & 0.149 \\
\hline $\mathrm{Hb}$ & $10.22 \pm 1.50$ & $10.202 \pm 1.48$ & $10.22 \pm 1.49$ & 0.884 \\
\hline Age at menarche & $13.40 \pm 0.73$ & $13.94 \pm 0.87$ & $13.76 \pm 0.86$ & $0.000 *$ \\
\hline Duration (days) & $3.89 \pm 2.25$ & $3.90 \pm 2.02$ & $3.90 \pm 2.10$ & 0.934 \\
\hline Interval (days) & $32.22 \pm 13.22$ & $34.79 \pm 23.02$ & $33.89 \pm 20.33$ & 0.165 \\
\hline Age at $\mathrm{I}^{\mathrm{st}}$ pregnancy & $19.43 \pm 2.06$ & $19.40 \pm 2.63$ & $19.43 \pm 2.44$ & 0.990 \\
\hline \multicolumn{5}{|l|}{ Contraceptive history } \\
\hline Not user & 125 & 238 & 363 & \\
\hline Modern methods & 39 & 50 & 89 & \\
\hline Ligation & 29 & 97 & 126 & $0.005^{*}$ \\
\hline \multicolumn{5}{|l|}{ Pallor } \\
\hline No pain & 7 & 149 & 156 & \\
\hline Pain & 186 & 239 & 425 & $0.000 *$ \\
\hline \multicolumn{5}{|l|}{ Healthy Cervix } \\
\hline No & 5 & 27 & 32 & \\
\hline Yes & 188 & 361 & 549 & $0.030 *$ \\
\hline \multicolumn{5}{|l|}{ Vaginal discharge } \\
\hline No & 66 & 121 & 187 & \\
\hline Yes & 127 & 267 & 394 & 0.464 \\
\hline \multicolumn{5}{|l|}{ Type of discharge } \\
\hline Copious & 10 & 20 & 30 & \\
\hline Curdy white & 24 & 27 & 51 & \\
\hline Mild & 16 & 16 & 32 & \\
\hline Mucoid & 10 & 29 & 39 & \\
\hline Yellowish & 0 & 14 & 14 & $0.005^{*}$ \\
\hline \multicolumn{5}{|l|}{ Type of morbidity } \\
\hline Contraceptive & 25 & 42 & 67 & \\
\hline Gynecology & 173 & 342 & 515 & \\
\hline Obstetrics & 23 & 37 & 60 & 0.774 \\
\hline \multicolumn{5}{|l|}{ Type of gynecological morbidity* } \\
\hline Reproductive tract infection & 72 & 169 & 241 & \\
\hline Menses & 57 & 157 & 214 & \\
\hline Infertility & 35 & 91 & 126 & \\
\hline Prolapse & 12 & 20 & 32 & \\
\hline others & 7 & 10 & 17 & 0.732 \\
\hline
\end{tabular}

*--Multiple responses

$58.3 \%$ from PHC had difficulty in micturition. Majority of women (96.9\%) were having an anterior vaginal wall prolapse with or without a uterine descent. None of the women with pelvic organ prolapse were nulliparous. The remaining number of women had symptoms of vesico vaginal fistula, perineal swelling, dysmenorrhoea and premenstrual syndrome.

Contraceptive morbidity was marginally more at PHC (36.76\%) than at SJH (28\%). Tubal ligation was the most common method used by women at both the centres (Table 3). Overall usage of

Int J Health Res, March 2011; 4(1): 32 
Table 3: Contraceptive used and morbidities*

\begin{tabular}{lllllll}
\hline \multirow{2}{*}{ Contraceptive } & \multicolumn{3}{c}{ SJH $(\mathrm{n}=42)$} & \multicolumn{2}{c}{ PHC $(\boldsymbol{n}=25)$} \\
\cline { 2 - 7 } & $\begin{array}{l}\text { contraceptive } \\
\text { morbidity }\end{array}$ & RTI & $\begin{array}{l}\text { Menstrual } \\
\text { dysfunction }\end{array}$ & $\begin{array}{l}\text { contraceptive } \\
\text { morbidity }\end{array}$ & RTI & $\begin{array}{l}\text { Menstrual } \\
\text { dysfunction }\end{array}$ \\
\hline Condom & 0 & 0 & 0 & $4(22.2 \%)$ & 0 & 0 \\
IUD & $12(85.7 \%)$ & $8(57.1 \%)$ & $3(21.4 \%)$ & $13(100 \%)$ & $7(53.8 \%)$ & $10(76.9 \%)$ \\
OCPs & $5(62.5 \%)$ & 0 & $4(50 \%)$ & $4(50 \%)$ & 0 & $4(50 \%)$ \\
DMPA & $1(100 \%)$ & 0 & $1(100 \%)$ & 0 & 0 & 0 \\
Ligation & $24(24.7 \%)$ & $16(16.5 \%)$ & $8(8.2 \%)$ & $4(13.8 \%)$ & $2(6.9 \%)$ & $2(6.9 \%)$ \\
\hline
\end{tabular}

*Multiple responses

Table 4: Type of obstetric morbidity

\begin{tabular}{llll}
\hline & SJH & PHC & Total \\
& & & \\
\hline Antenatal & $16(43.24 \%)$ & $10(43.48 \%)$ & $26(43.33 \%)$ \\
Swelling of Hands and Feet & $7(19.44 \%)$ & $2(8.7 \%)$ & $9(9.9 \%)$ \\
Symptomatic Anemia & $10(27.78 \%)$ & $3(13.04 \%)$ & $13(14.3 \%)$ \\
Natal & $27(72.97 \%)$ & $11(47.83 \%)$ & $38(63.33 \%)$ \\
Difficult Delivery & $10(27.78 \%)$ & $6(26.09 \%)$ & $16(17.6 \%)$ \\
Excessive Bleeding & $3(8.33 \%)$ & $3(13.04 \%)$ & $6(6.6 \%)$ \\
Retained Placenta & $1(2.78 \%)$ & 0 & $1(1.1 \%)$ \\
Pus Formation In Tear & $2(5.56 \%)$ & 0 & $2(2.2 \%)$ \\
Fever>3 Days & $8(22.22 \%)$ & $5(21.74 \%)$ & $13(14.3 \%)$ \\
Postpartum & $20(54.05 \%)$ & $18(78.26 \%)$ & $38(63.33 \%)$ \\
Burning Micturition & $6(16.67 \%)$ & $5(21.74 \%)$ & $11(12.1 \%)$ \\
Foul Smelling Discharge & $8(22.22 \%)$ & $3(13.04 \%)$ & $11(12.1 \%)$ \\
Excess Bleeding & $4(11.11 \%)$ & $4(17.39 \%)$ & $8(8.8 \%)$ \\
Prolonged Discharge after Delivery & $6(16.67 \%)$ & $5(21.74 \%)$ & $11(12.1 \%)$ \\
\hline
\end{tabular}

condom, IUD and oral contraceptive pills was more at PHC. All the users of IUD at PHC and $85.7 \%$ women at $\mathrm{SJH}$ reported some complaint or the other suggestive of rTI. Morbidity was seen least among users of barrier methods $(22.2 \%)$ at the PHC and none at SJH. Women using other forms of contraceptives attributed menstrual dysfunction to its use.

Out of the 581 women, 91 were found to have conceived in the past two years. Amongst these, 60 women $(65.93 \%)$ reported at least one condition indicative of having had an obstetric morbidity (Table 4). Some of these pregnancies $(4.4 \%)$ had resulted in a stillbirth. Some women $87.9 \%$ had a normal vaginal delivery while 10 (11\%) had a cesarean section. Half of the deliveries were conducted by untrained traditional birth attendants (dais) and more than half of the women delivered at home. The frequency of antenatal symptoms was similar in both the centres $(43.3 \%)$. The most commonly quoted symptom was that of anemia (14.3\%), followed by clinical pallor, swelling of hands and feet with a high documented blood pressure being the next most common symptoms. Intrapartum morbidity was reported more often at $\mathrm{SJH}$ $(72.9 \%)$ than at the PHC $(47 \%)$. A higher proportion of women had developed postpartum complications $(78 \%)$ at $\mathrm{PHC}$ as compared to the SJH (54\%). The most common symptoms were those of postpartum pyrexia (14.3\%), foul smelling discharge $((12 \%)$, prolonged and persistent discharge (12\%) and prolapse (9.9\%).

\section{Discussion}

The mean age of women in our study was 29.64 yr which generally corresponds to the peak reproductive age when a woman is usually married and has borne children in India. In the present study, majority of the women complained

Int J Health Res, March 2011; 4(1): 33 
of some gynecologic morbidity (88.64\%) with an almost similar pattern at both centres which is similar to the $70 \%$ to $92 \%$ earlier reported. ${ }^{5-8}$ Among women who reported gynecologic morbidity, symptoms suggestive of rTI were most commonly followed by menstrual irregularity similar to the findings reported by Bonetti, Erpelding and Pathak ${ }^{8}$ and Garg et $\mathrm{al}^{7}$. However, a study by Zafar and Mahmood ${ }^{9}$ observed a lower frequency of rTI. They observed menstrual irregularity $(41.1 \%)$ to be the most common morbidity followed by rTIs $(27.8 \%)$, subfertility (18.2\%) and urogynecological problems (5.3\%).

The frequency of infertility $(21.69 \%)$ reported was high as compared to earlier research. $5,6,8,9$ This may be explained in part by the fact that the present study was clinic-based study unlike the community-based study, which could have introduced a bias by more women with infertility reporting to the centers than what would be observed in a community study. Majority of women with pelvic organ prolapse had an onset after 30 years of age. Prolapse was more frequent in Bonetti, Erpelding and Pathak. ${ }^{8}$ This difference could be explained by the different geographic locations and the fact that in their study women reported carrying heavy loads every day which was not similar to our study.

Overall, $11.5 \%$ women attributed their complaints to their present contraceptive use. Wasserheit (1989) reported that 22\% of the 2929 women using contraception had symptoms of rTI. ${ }^{10}$ The National Family Health Survey (NFHS) reported that $19 \%$ of the IUD and $23.3 \%$ of tubal ligation reported at least one problem related to its use. ${ }^{11}$ Community-based studies in India on reproductive health have consistently shown that the prevalence of self reported symptoms of rTIs are relatively high among contraceptive users than in non-users. ${ }^{12}$ In the present study, one in every three women using contraception had some complaint they attributed to their present contraceptive use. IUD users reported morbidity most often followed by women who had undergone tubal ligation and couples using barrier methods for contraception. Both IUD users and sterilization acceptors had a higher chance of experiencing menstrual problems similar to findings by NFHS and
Sowmini and Sankara. ${ }^{11,13}$ An analysis of rural and urban women revealed that a higher proportion $(39.9 \%)$ of urban women as compared to $34.4 \%$ of rural women were presently using some form of contraception.

Information on obstetric morbidity was collected only by interview-questionnaire method from women who had experienced pregnancy in the last two years. Two-thirds of women at each of the centres reported some obstetric morbidity on recall of their last pregnancy. This information represents self-reporting that unfortunately could not be validated by a medical report. In a community-based study by Chowdhury, Akhter and Chongvivatwong the prevalence of obstetric morbidity was similar. ${ }^{14}$ On the other hand, reported obstetric morbidity was lower in a study by Goodburn at 33\% and Bhatia and Cleland at $40 \%$. ${ }^{15,12}$ Most women in our study were of a low socioeconomic status and had low literacy levels. They did not receive any antenatal care with half of the deliveries being conducted by untrained dais at home. These observations were in common with the study by Chowdhury, Akhter and Chongvivatwong and probably accounted for high obstetric morbidity in the present study. ${ }^{14}$ These findings were similar to the national average of $42.6 \%$ deliveries being conducted by Trained Birth Attendants (TBAs). Similar findings were reported by Zurayk et al. ${ }^{16}$ In our study, intrapartum and postpartum morbidities were reported most commonly in each category, while Bhatia and Cleland reported postpartum morbidities to be the most common in their study. ${ }^{17}$ During the postpartum period, reported symptoms were postpartum pyrexia, foul smelling discharge and excess bleeding similar to those reported by Zurayk et al and Bhatia and Cleland (1996). ${ }^{16,17}$

\section{Conclusion}

Reproductive morbidities in the present study were observed to be quite high with gynecological morbidity being the most common, followed by obstetric and contraceptive morbidities. The fact that one in every ten women was harbouring rTI asymptomatically emphasizes the need of encouraging regular check-ups for

Int J Health Res, March 2011; 4(1): 34 
early identification of RTI cases. The health care system also needs to be strengthened such that the practice of conducting births supervised by untrained traditional birth attendants is discouraged. This accentuates the priority to work with women at the community level to improve their reproductive health.

\section{Contribution of Authors}

We declare that this work was done by the authors named in this article and all liabilities pertaining to claims relating to the content of this article will be borne by the authors. The study was conceived and designed by SS, SR, VT and HSG. The data was collected by SR and analysed by VT. The manuscript is part of MD thesis of SR. The final manuscript was prepared by SR, HSG and VT. All authors contributed to the preparation of the manuscript and approved of its contents.

\section{References}

1. WHO. Declaration of Alma-Ata, 1978. Accessed on 20 January, 2011. http://www.who.int/hpr/NPH/docs/ declaration_almaata.pdf

2. WHO. Interpreting reproductive health. ICPD +5 Forum, The Hague, Netherlands 8-12 February 1999. Geneva: World Health Organisation, 1999 (Document No WHO/CHS/RHR/99.7).

3. Fathalla MF. Research needs in human reproduction. In: Diczfalusy E, Griffin PD, and Khanna J, eds. Research in human reproduction: biennial report 1986-1987. Geneva: WHO, 1988.

4. WHO. 'Report on the regional reproductive health strategy workshop: South-East Asia region.' Geneva: World Health Organization, 1995.

5. Bang R, Bang A, Baitule $M$ et al. High prevalence of gynecological diseases in rural Indian Women. Lancet 1989; 1(8629): 85-88.
Reproductive Morbidities Among Women

6. Walraven G, Scherf C, West B, et al. The burden of reproductive-organ disease in rural women in The Gambia, West Africa. Lancet 2001 Apr 14; 357 (9263):1161-7.

7. Garg S, Sharma N, Bhalla P, et al. Reproductive morbidity in an Indian urban slum: need for health action. Sex Transm Infect 2002; 78(1): 68-69.

8. Bonetti TR, Erpelding A and Pathak LR. Reproductive Morbidity- a neglected issue? A Report of a Clinic-based Study Held in Far-Western Nepal. Kathmandu: Ministry of Health/ GTZ/ UNFPA, 2002.

9. Zafar, S and Mahmood G. Burden of gynaecological disease in a Tertiary Hospital: Two-years audit of Outpatient Department at PIMS. J Pak Med Assoc 54: 513-516.

10. Wasserheit J.N. The significance and scope of reproductive tract infections among third world women. Int J Gynecol Obstet 1989; 3 (S1):145-68.

11. Ministry of Health and Family Welfare. Concurrent Evaluation of Family Welfare Program: Second report (period 1989-90). New Delhi: MOHFW, 1991.

12. Bhatia JC, Cleland J. Self reported symptoms of gynecological morbidity and their treatment in South India. Stu. Family Planning 1995; 26(4): 203-216.

13. Sowmini C.V and Sankara Sarma P. Reproductive morbidity among contraceptive users: need for quality services. Indian J Fam Welfare 2004; 50(1):31-38.

14. Chowdhury ME, Akhter $\mathrm{HH}$, Chongsvivatwong V. Community based self reported symptoms of antepartum morbidities; the health burden and care- seeking patterns of rural Bangladeshi women. Southeast Asian J Trop Med Public Health 2000; 31:598-605.

15. Goodburn EA. A Prospective Study of maternal morbidity related to delivery and the puerperium in rural Bangladesh. London: London School of Hygiene and Tropical Medicine, 1997 (Ph.D thesis).

16. Zurayk H, Khattab H, Younis N, El-Mouelhy M, Fadle M. Concepts and Measures of reproductive morbidity. Health Transit Rev. 1993; 3 (1):17-40.

17. Bhatia JC, Cleland J. Obstetric morbidity in South India: results from a community survey: Soc Sci Med 1996; 43(10):1507-16. 
Int J Health Res, March 2011; 4(1): 36 